\section{THE APPLICATIONS OF ZERO DIVISORS OF SOME FINITE RINGS OF MATRICES IN PROBABILITY AND GRAPH THEORY}

\author{
Nurhidayah Zaida, Nor Haniza Sarmina*, Sanhan Muhammad Salih \\ Khasrawb
}

aDepartment of Mathematical Sciences, Faculty of Science, Universiti Teknologi Malaysia, 81310 UTM Johor Bahru, Johor, Malaysia bDepartment of Mathematics, College of Basic Education, Salahaddin University-Erbil, Kurdistan Region, Iraq
Article history

Received

26 April 2020

Received in revised form

25 November 2020

Accepted

3 December 2020

Published online

17 December 2020

\section{*Corresponding author}

nhs@utm.my

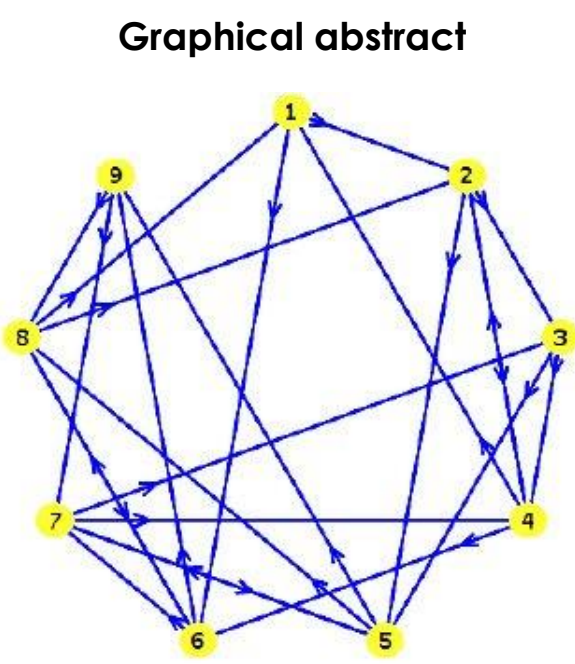

\begin{abstract}
Let $R$ be a finite ring. The zero divisors of $R$ are defined as two nonzero elements of $R$, say $x$ and $y$ where $x y=0$. Meanwhile, the probability that two random elements in a group commute is called the commutativity degree of the group. Some generalizations of this concept have been done on various groups, but not in rings. In this study, a variant of probability in rings which is the probability that two elements of a finite ring have product zero is determined for some ring of matrices over integers modulo $n$. The results are then applied into graph theory, specifically the zero divisor graph. This graph is defined as a graph where its vertices are zero divisors of $R$ and two distinct vertices $x$ and $y$ are adjacent if and only if $x y=0$. It is found that the zero divisor graph of $R$ is a directed graph.
\end{abstract}

Keywords: Zero divisor, ring theory, ring of matrices, graph theory, zero divisor graph

\begin{abstract}
Abstrak
Andaikan $R$ sebagai sebuah gelanggang terhingga. Pembahagi sifar bagi $R$ ditakrifkan sebagai dua unsur bukan sifar bagi $R$, katakan $x$ dan y di mana $x y$ $=0$. Sementara itu, kebarangkalian dua unsur rawak dalam sebuah kumpulan bertukar tertib digelar sebagai darjah kekalisan tukar tertib. Beberapa pengitlakan kepada konsep ini telah dijalankan ke atas pelbagai kumpulan, tetapi tidak ke atas gelanggang. Dalam kajian ini, satu kelainan bagi kebarangkalian di dalam gelanggang iaitu kebarangkalian dua unsur bagi suatu gelanggang terhingga mempunyai hasil kosong telah ditentukan untuk beberapa gelanggang matriks terhingga di atas integer-integer bermodulo $n$. Keputusan yang diperoleh kemudian diaplikasi ke dalam teori graf, secara khususnya graf pembahagi sifar. Graf ini ditakrifkan sebagai sebuah graf di mana bucu-bucunya adalah pembahagi sifar bagi $R$ dan dua bucu berlainan $x$ dan $y$ adalah bersambung jika dan hanya jika $x y=0$. Adalah ditemukan bahawa graf pembahagi sifar bagi $R$ merupakan sebuah graf terarah.

Kata kunci: Pembahagi sifar, teori gelanggang, gelanggang matriks, teori graf, graf pembahagi sifar
\end{abstract}

(C) 2021 Penerbit UTM Press. All rights reserved 


\subsection{INTRODUCTION}

In mathematics, mainly in the area of algebra, ring theory has been studied in many researches and it has been applied in various fields such as computer science [1], cryptography [2] and image segmentation [3]. A set $R$ is said to be a ring if it is an abelian group by addition, associative by multiplication and satisfies the left and right distributive law [4].

One of the interesting elements of a ring is the zero divisors. The zero divisors of $R$ are defined as two nonzero elements of $R$, say $x$ and $y$ where the product of $x$ and $y$ is zero [4]. A ring which does not have any zero divisor is called an integral domain [5].

Meanwhile, probability theory has been widely used in determining some properties of finite groups and rings. One of the examples is the commutativity degree. Commutativity degree of a group is the probability that two random elements of a group commute [6]. This concept has been used not only in groups, but also in rings [7].

In addition, another branch of mathematics, which is graph theory has also been applied in many areas including computer science [8], physics [9], chemistry [10], group theory [11] as well as ring theory [12]. Since graph is a method to show the relation between two objects, the research on topics in ring theory can also be modelled in this form.

In this article, the study focuses on rings, probability and graphs. The study starts by determining the zero divisors of some ring of matrices over integers modulo $n$. The results are then used to determine a type of probability in rings, namely the probability that two elements of a ring have product zero. Lastly, the zero divisor graph is constructed by using the zero divisors obtained with the assistance of Maple soft ware.

\subsection{PRELIMINARIES}

In this section, some basic definitions in rings, probability and graphs which are used in this study are provided. The methodology used in this study will also be included. This section starts by providing the definition of a ring.

Definition 2.1 [4] Ring

A ring $\langle R,+, \cdot\rangle$ is a set $R$ together with two binary operations + and $\cdot$, which are called addition and multiplication, defined on $R$ such that the following axioms are satisfied:

(i) $\langle R,+\rangle$ is an abelian group.

(ii) Multiplication is associative.

(iii) For all $a, b, c \in R$, the left distributive law, $a \cdot(b+c)=(a \cdot b)+(a \cdot c)$ and the right distributive law $(a+b) \cdot c=(a \cdot c)+(b \cdot c)$ hold.

Definition 2.2 [13] Commutative Ring

A ring $R$ is commutative, if $a b=b a$ for all $a, b \in R$.
Definition 2.3 [13] Matrix Operations

Let $M_{n}(R)$ be a ring of $n \times n$ matrices with entries in a given $R$, as follows: each matrix is written as $\left(r_{i j}\right)$ where $r_{i j}$ denotes the $i-j$ entry for $1 \leq i, j \leq n$; addition and multiplication are given according to the rules:

$$
\begin{aligned}
& \text { (i) }\left(r_{i j}^{(1)}\right)+\left(r_{i j}^{(2)}\right)=\left(r^{(1)}+r_{i j}^{(2)}\right) \\
& \text { (ii) }\left(r_{i j}^{(1)}\right)\left(r_{i j}^{(2)}\right)=\left(r_{i j}^{(3)}\right) \text {, where }\left(r_{i j}^{(3)}\right)=\sum_{k=1}^{n} r_{i k}^{(1)} r_{k j}^{(2)} \text {. }
\end{aligned}
$$

In this article, the rings that are taken into consideration are noncommutaive rings, which are the ring of $2 \times 2$ matrices over integers modulo $n$, where $n=2$ and 3 . The rings can also be written as $M_{2}\left(\mathbb{Z}_{2}\right)$ and $M_{2}\left(\mathbb{Z}_{3}\right)$. From each ring, the zero divisors are determined. The definition of the zero divisors of a ring is given in the following:

Definition 2.4 [4] Zero Divisor of a Ring

If $a$ and $b$ are two nonzero elements of $a$ ring $R$ such that $a b=0$, then $a$ and $b$ are the zero divisors of $R$.

Next, some concepts of probability theory in groups as well as rings are presented. Probability theory has been widely used in group theory. One of the examples is the commutativity degree of a group, which is introduced by Gustafson [6] in 1973. The definition is given as:

Definition 2.5 [6] Commutativity Degree

Let $G$ be a group of finite order $n$. The commutativity degree or the probability, $\operatorname{Pr}(G)$ that two elements selected at random (with replacement) from $G$ are commutative is:

$$
\operatorname{Pr}(G)=\frac{\{(x, y) \in G \times G \mid x y=y x\} \mid}{n^{2}} .
$$

This concept has been determined in various nonabelian groups and many researches have been done on its extension, such as the probability that an automorphism fixes a group element [14], the relative commutativity degree [15] and the conjugation degree [16].

Afterwards, the concept of commutativity degree has gathered the attention of ring theorists too. For instance, MacHale [17] in 1976 has determined the probability that two random elements of a ring commute for noncommutative rings. Later on, Buckley et al. [18] have extended the research and found the probability that a random pair of elements in a finite ring commute by isoclinism.

Recently, based on the idea of commutativity degree and zero divisor of a finite ring, Khasraw [19] has introduced a new concept of probability in finite rings, which is the probability that two elements of a finite ring have product zero. The definition is given as follows:

Definition 2.5 [19] Probability that Two Elements of a Ring Have Product Zero

Let $R$ be a finite ring. The probability that two elements chosen at random (with replacement) from a ring $R$ have product zero is: 


$$
P(R)=\frac{|A n n(R)|}{|R \times R|},
$$

where $A n n(R)=\{(x, y) \in R \times R \mid x y=0\}$.

In this paper, the annihilators, Ann are determined for $M_{2}\left(\mathbb{Z}_{2}\right)$ and $M_{2}\left(\mathbb{Z}_{3}\right)$. Then, the probability that two elements of the rings have product zero is calculated.

Moreover, both groups and rings are often related to graph theory. Graph is a mathematical structure consisting of two sets which are the vertices and edges [20]. A simple graph is defined as a graph with no self-loops or multi edges [21].

In this study, a simple graph which is the zero divisor graph is constructed for $M_{2}\left(\mathbb{Z}_{2}\right)$ and $M_{2}\left(\mathbb{Z}_{3}\right)$ to show the relation of the zero divisors of the rings and their products. The zero divisor graph is defined in the following definition.

Definition 2.6 [22] Zero Divisor Graph

Let $R$ be a commutative ring and let $Z(R)$ be its set of zero divisors. The zero divisor graph, $\Gamma(R)$ is a graph of $R$ with vertices $Z(R)^{*}=Z(R)-\{0\}$, the set of nonzero zero divisors of $R$, and for distinct $x, y \in Z(R)^{*}$, the vertices $x$ and $y$ are adjacent if and only if $x y=0$.

It can be seen that two vertices are adjacent if they are in the set of annihilators, hence form an arc in the graph.

In 2002, Redmond [23] has studied the zero divisor graph of noncommutative rings and found that the zero divisor graph of a noncommutative ring is a directed graph.

In the next section, the results obtained in this study are presented.

\subsection{RESULTS AND DISCUSSION}

This section consists of three parts, the first part focuses on determining the zero divisors of the finite rings $R_{1}=M_{2}\left(\mathbb{Z}_{2}\right)$ and $R_{2}=M_{2}\left(\mathbb{Z}_{3}\right)$. Then, the second part focuses on computing the probability that two elements of $R_{1}$ and $R_{2}$ have product zero, while the third part applies the obtained results to graph theory, specifically the zero divisor graph.

\subsection{The Zero Divisors of Finite Rings $R_{1}$ and $R_{2}$}

In this subsection, the zero divisors of finite rings $R_{1}=M_{2}\left(\mathbb{Z}_{2}\right)$ and $R_{2}=M_{2}\left(\mathbb{Z}_{3}\right)$ are determined by using its definition, as stated in Definition 2.4.

Lemma 3.1 Let $R_{1}=\left\{\left[\begin{array}{ll}a & b \\ c & d\end{array}\right] \mid a, b, c, d \in \mathbb{Z}_{2}\right\}$ be a finite ring. Then, $R_{1}$ has nine zero divisors.
Proof: Let $R_{1}=\left\{\left[\begin{array}{ll}a & b \\ c & d\end{array}\right] \mid a, b, c, d \in \mathbb{Z}_{2}\right\}$. The number of elements of $R_{1}$ is $\left|R_{1}\right|=2^{2 \times 2}=2^{4}=16$. The elements of $R_{1}$ are listed as follows:

$$
\begin{aligned}
R_{1}= & \left\{\left[\begin{array}{ll}
0 & 0 \\
0 & 0
\end{array}\right],\left[\begin{array}{ll}
0 & 0 \\
0 & 1
\end{array}\right],\left[\begin{array}{ll}
0 & 0 \\
1 & 0
\end{array}\right],\left[\begin{array}{ll}
0 & 1 \\
0 & 0
\end{array}\right],\left[\begin{array}{ll}
1 & 0 \\
0 & 0
\end{array}\right],\left[\begin{array}{ll}
0 & 0 \\
1 & 1
\end{array}\right],\left[\begin{array}{ll}
0 & 1 \\
0 & 1
\end{array}\right],\right. \\
& {\left[\begin{array}{ll}
1 & 0 \\
0 & 1
\end{array}\right],\left[\begin{array}{ll}
0 & 1 \\
1 & 0
\end{array}\right],\left[\begin{array}{ll}
1 & 0 \\
1 & 0
\end{array}\right],\left[\begin{array}{ll}
1 & 1 \\
0 & 0
\end{array}\right],\left[\begin{array}{ll}
0 & 1 \\
1 & 1
\end{array}\right],\left[\begin{array}{ll}
1 & 1 \\
1 & 0
\end{array}\right],\left[\begin{array}{ll}
1 & 0 \\
1 & 1
\end{array}\right], } \\
& {\left.\left[\begin{array}{ll}
1 & 1 \\
0 & 1
\end{array}\right],\left[\begin{array}{ll}
1 & 1 \\
1 & 1
\end{array}\right]\right\} . }
\end{aligned}
$$

By using Definition 2.4, the zero divisors of $R_{1}$ are obtained. The zero element of $R_{1}$ is $\left[\begin{array}{ll}0 & 0 \\ 0 & 0\end{array}\right]$. Hence, all pair of elements of $R_{1}$ (hence the zero divisors) in which their product is equal to $\left[\begin{array}{ll}0 & 0 \\ 0 & 0\end{array}\right]$ are determined. For example, $\left[\begin{array}{ll}0 & 0 \\ 1 & 0\end{array}\right]\left[\begin{array}{ll}0 & 0 \\ 0 & 1\end{array}\right]=\left[\begin{array}{ll}0 & 0 \\ 0 & 0\end{array}\right]$. Therefore, $\left[\begin{array}{ll}0 & 0 \\ 1 & 0\end{array}\right]$ and $\left[\begin{array}{ll}0 & 0 \\ 0 & 1\end{array}\right]$ are the zero divisors of $R_{1}$. After performing the calculations manually, it is found that $R_{1}$ has nine zero divisors. The set of zero divisors of $R_{1}, Z\left(R_{1}\right)$ is written as:

$$
\begin{aligned}
& Z\left(R_{1}\right)=\left\{\left[\begin{array}{ll}
0 & 0 \\
1 & 0
\end{array}\right],\left[\begin{array}{ll}
0 & 0 \\
0 & 1
\end{array}\right],\left[\begin{array}{ll}
0 & 1 \\
0 & 0
\end{array}\right],\left[\begin{array}{ll}
1 & 0 \\
0 & 0
\end{array}\right],\left[\begin{array}{ll}
1 & 1 \\
0 & 0
\end{array}\right],\left[\begin{array}{ll}
0 & 0 \\
1 & 1
\end{array}\right],\right. \\
& {\left.\left[\begin{array}{ll}
0 & 1 \\
0 & 1
\end{array}\right],\left[\begin{array}{ll}
1 & 0 \\
1 & 0
\end{array}\right],\left[\begin{array}{ll}
1 & 1 \\
1 & 1
\end{array}\right]\right\} . }
\end{aligned}
$$

Lemma 3.2 Let $R_{2}=\left\{\left[\begin{array}{ll}a & b \\ c & d\end{array}\right] \mid a, b, c, d \in \mathbb{Z}_{3}\right\}$ be a finite ring. Then, $R_{2}$ has 32 zero divisors.

Proof: Let $R_{2}=\left\{\left[\begin{array}{ll}a & b \\ c & d\end{array}\right] \mid a, b, c, d \in \mathbb{Z}_{3}\right\}$. The number of elements in $R_{2}$ is $\left|R_{2}\right|=3^{2 \times 2}=3^{4}=81$. By using Definition 2.4 and similar method as Lemma 3.1, it is found that the ring $R_{2}$ has 32 zero divisors. The set of zero divisors of $R_{2}$ is given in the following.

$$
\begin{aligned}
Z\left(R_{2}\right)= & \left\{\left[\begin{array}{ll}
0 & 0 \\
0 & 1
\end{array}\right],\left[\begin{array}{ll}
0 & 0 \\
0 & 2
\end{array}\right],\left[\begin{array}{ll}
0 & 0 \\
1 & 0
\end{array}\right],\left[\begin{array}{ll}
0 & 0 \\
1 & 1
\end{array}\right],\left[\begin{array}{ll}
0 & 0 \\
1 & 2
\end{array}\right],\left[\begin{array}{ll}
0 & 0 \\
2 & 0
\end{array}\right],\right. \\
& {\left[\begin{array}{ll}
0 & 0 \\
2 & 1
\end{array}\right],\left[\begin{array}{ll}
0 & 0 \\
2 & 2
\end{array}\right],\left[\begin{array}{ll}
0 & 1 \\
0 & 0
\end{array}\right],\left[\begin{array}{ll}
0 & 1 \\
0 & 1
\end{array}\right],\left[\begin{array}{ll}
0 & 1 \\
0 & 2
\end{array}\right],\left[\begin{array}{ll}
0 & 2 \\
0 & 0
\end{array}\right], } \\
& {\left[\begin{array}{ll}
0 & 2 \\
0 & 1
\end{array}\right],\left[\begin{array}{ll}
0 & 2 \\
0 & 2
\end{array}\right],\left[\begin{array}{ll}
1 & 0 \\
0 & 0
\end{array}\right],\left[\begin{array}{ll}
1 & 0 \\
1 & 0
\end{array}\right],\left[\begin{array}{ll}
1 & 0 \\
2 & 0
\end{array}\right],\left[\begin{array}{ll}
1 & 1 \\
0 & 0
\end{array}\right], } \\
& {\left[\begin{array}{ll}
1 & 1 \\
1 & 1
\end{array}\right],\left[\begin{array}{ll}
1 & 1 \\
2 & 2
\end{array}\right],\left[\begin{array}{ll}
1 & 2 \\
0 & 0
\end{array}\right],\left[\begin{array}{ll}
1 & 2 \\
1 & 2
\end{array}\right],\left[\begin{array}{ll}
1 & 2 \\
2 & 1
\end{array}\right],\left[\begin{array}{ll}
2 & 0 \\
0 & 0
\end{array}\right], }
\end{aligned}
$$




$$
\begin{aligned}
& {\left[\begin{array}{ll}
2 & 0 \\
1 & 0
\end{array}\right],\left[\begin{array}{ll}
2 & 0 \\
2 & 0
\end{array}\right],\left[\begin{array}{ll}
2 & 1 \\
0 & 0
\end{array}\right],\left[\begin{array}{ll}
2 & 1 \\
1 & 2
\end{array}\right],\left[\begin{array}{ll}
2 & 1 \\
2 & 1
\end{array}\right],\left[\begin{array}{ll}
2 & 2 \\
0 & 0
\end{array}\right],} \\
& \left.\left[\begin{array}{ll}
2 & 2 \\
1 & 1
\end{array}\right],\left[\begin{array}{ll}
2 & 2 \\
2 & 2
\end{array}\right]\right\} .
\end{aligned}
$$

3.2 The Probability that Two Elements of $R_{1}$ and $R_{2}$ have Product Zero

This subsection presents the results on the probability that two elements of a finite ring have product zero for the rings $R_{1}$ and $R_{2}$.

Proposition 3.1 Let $R_{1}=\left\{\left[\begin{array}{ll}a & b \\ c & d\end{array}\right] \mid a, b, c, d \in \mathbb{Z}_{2}\right\}$ be $a$ finite ring. Then $R_{1}$ has 58 annihilators and the probability that two elements of $R_{1}$ have product zero is $P\left(R_{1}\right)=\frac{29}{128}$.

Proof: Let $R_{1}=\left\{\left[\begin{array}{ll}a & b \\ c & d\end{array}\right] \mid a, b, c, d \in \mathbb{Z}_{2}\right\}$. Referring to Definition 2.5, the set of annihilators of $R_{1}$ is defined as Ann $\left(R_{1}\right)=\left\{(x, y) \in R_{1} \times R_{1} \mid x y=\left[\begin{array}{ll}0 & 0 \\ 0 & 0\end{array}\right]\right\}$ for all $x$ and $y$ in $R_{1}$. By using this definition with the assistance of the zero divisors obtained in Lemma 3.1, the annihilators of $R_{1}$ are determined.

Since any $x \in R_{1}$ multiplied with the zero matrix will equal to the zero matrix itself, hence it is confirmed that there will be at least $2|R|-1$ annihilators of $R_{1}$. In addition, referring to Lemma 3.1, the annihilators are determined for all zero divisors of $R_{1}$ by using its definition.

It is found that $R_{1}$ has a total of 58 annihilators, which includes the pairs in the following:

$\left(\left[\begin{array}{ll}0 & 0 \\ 0 & 0\end{array}\right],\left[\begin{array}{ll}0 & 0 \\ 0 & 0\end{array}\right]\right),\left(\left[\begin{array}{ll}0 & 0 \\ 1 & 0\end{array}\right],\left[\begin{array}{ll}0 & 0 \\ 0 & 1\end{array}\right]\right),\left(\left[\begin{array}{ll}0 & 0 \\ 1 & 1\end{array}\right],\left[\begin{array}{ll}1 & 0 \\ 1 & 0\end{array}\right]\right)$ and $\left(\left[\begin{array}{ll}1 & 1 \\ 0 & 0\end{array}\right] \cdot\left[\begin{array}{ll}1 & 1 \\ 1 & 1\end{array}\right]\right)$.

Hence, by using Definition 2.5, the probability that two elements of $R_{1}$ have product zero is $P\left(R_{1}\right)=\frac{58}{16 \times 16}$ $=\frac{29}{128}$.

Proposition 3.2 Let $R_{2}=\left\{\left[\begin{array}{ll}a & b \\ c & d\end{array}\right] \mid a, b, c, d \in \mathbb{Z}_{3}\right\}$ be a finite ring. Then, Then $R_{2}$ has 417 annihilators and the probability that two elements of $R_{2}$ have product zero is $P\left(R_{2}\right)=\frac{139}{2187}$.
Proof: Let $R_{2}=\left\{\left[\begin{array}{ll}a & b \\ c & d\end{array}\right] \mid a, b, c, d \in \mathbb{Z}_{3}\right\}$. First, the annihilators are determined by using its definition with the assistance of the results on the zero divisors of $R_{2}$ in Lemma 3.2. It is found that the set of annihilators of ring $R_{2}$, $A n n\left(R_{2}\right)$ has 417 elements.

Therefore, by using Definition 2.5, the probability that two elements of $R_{2}$ has product zero, $P\left(R_{2}\right)=\frac{417}{81 \times 81}=\frac{139}{2187}$.

\subsection{The Zero Divisor Graph of $\boldsymbol{R}_{1}$ and $\boldsymbol{R}_{2}$}

In this subsection, the results on the zero divisor graph of $R_{1}$ and $R_{2}$ are provided in the form of propositions.

Proposition 3.3 Let $R_{1}=\left\{\left[\begin{array}{ll}a & b \\ c & d\end{array}\right] \mid a, b, c, d \in \mathbb{Z}_{2}\right\}$ be a finite ring. Then, the zero divisor graph of $R_{1}, \Gamma\left(R_{1}\right)$ is a directed graph with nine vertices and 24 arcs.

Proof: Let $R_{1}=\left\{\left[\begin{array}{ll}a & b \\ c & d\end{array}\right] \mid a, b, c, d \in \mathbb{Z}_{2}\right\}$. Recall from

Definition 2.6, zero divisor graph is a simple graph where its vertices are the set of zero divisors of a ring $R$ and two vertices are adjacent if and only if the product of the zero divisors is the zero element of $R$.

From Lemma 3.1, the set of zero divisors of $R_{1}$ has been determined, which is

$$
\begin{aligned}
Z\left(R_{1}\right)= & \left\{\left[\begin{array}{ll}
0 & 0 \\
1 & 0
\end{array}\right],\left[\begin{array}{ll}
0 & 0 \\
0 & 1
\end{array}\right],\left[\begin{array}{ll}
0 & 1 \\
0 & 0
\end{array}\right],\left[\begin{array}{ll}
1 & 0 \\
0 & 0
\end{array}\right],\left[\begin{array}{ll}
1 & 1 \\
0 & 0
\end{array}\right],\left[\begin{array}{ll}
0 & 0 \\
1 & 1
\end{array}\right],\right. \\
& {\left.\left[\begin{array}{ll}
0 & 1 \\
0 & 1
\end{array}\right],\left[\begin{array}{ll}
1 & 0 \\
1 & 0
\end{array}\right],\left[\begin{array}{ll}
1 & 1 \\
1 & 1
\end{array}\right]\right\} . }
\end{aligned}
$$

Since $R_{1}$ has nine zero divisors, then the zero divisor graph of $R_{1}, \Gamma\left(R_{1}\right)$ has nine vertices. Each zero divisor of $R_{1}$ as stated in $Z\left(R_{1}\right)$ represents one vertex of $\Gamma\left(R_{1}\right)$, from 1 to 9 , respectively.

Then, the arcs of the graph $\Gamma\left(R_{1}\right)$ are constructed based on the annihilators of $R_{1}$ which have been determined in Proposition 3.1. From Proposition 3.1, it has been found that $R_{1}$ has 58 annihilators. Since the vertices of the graph are the zero divisors (which exclude the zero matrix), hence all annihilators which involve the zero matrix are excluded. Besides that, since the zero divisor graph is a simple graph, all annihilators $(x, y) \in A n n\left(R_{1}\right)$ in which $x=y$ are also excluded to avoid creating a self-loop on some vertices. Hence, it is found that $\Gamma\left(R_{1}\right)$ has 24 arcs.

Therefore, $\Gamma\left(R_{1}\right)$ is a directed graph with nine vertices and 24 arcs, as shown in Figure 1. 


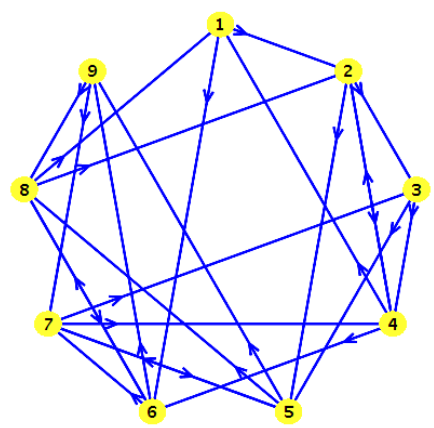

Figure 1 The zero divisor graph of the finite ring $R_{1}$

Proposition 3.4 Let $R_{2}=\left\{\left[\begin{array}{ll}a & b \\ c & d\end{array}\right] \mid a, b, c, d \in \mathbb{Z}_{3}\right\}$ be $a$ finite ring. Then, the zero divisor graph of $R_{2}, \Gamma\left(R_{2}\right)$ is a directed graph with 32 vertices and 248 arcs.

Proof: Let $R_{2}=\left\{\left[\begin{array}{ll}a & b \\ c & d\end{array}\right] \mid a, b, c, d \in \mathbb{Z}_{3}\right\}$. First, the zero divisors of $R_{2}$ are determined. Referring to Lemma $3.2, R_{2}$ has 32 zero divisors, which are represented by the vertices 1 to 32 respectively in the zero divisor graph of $R_{2}, \Gamma\left(R_{2}\right)$. Hence, it is known that $\Gamma\left(R_{2}\right)$ has 32 vertices.

Then, with the help of the computations on annihilators in Proposition 3.2, excluding the cases involving the zero matrix, as well as the case where $(x, y) \in A n n\left(R_{2}\right)$ in which $x=y$, it is found that $\Gamma\left(R_{2}\right)$ has 248 arcs.

Therefore, $\Gamma\left(R_{2}\right)$ is a directed graph with 32 vertices and 248 arcs, which is shown in Figure 2.

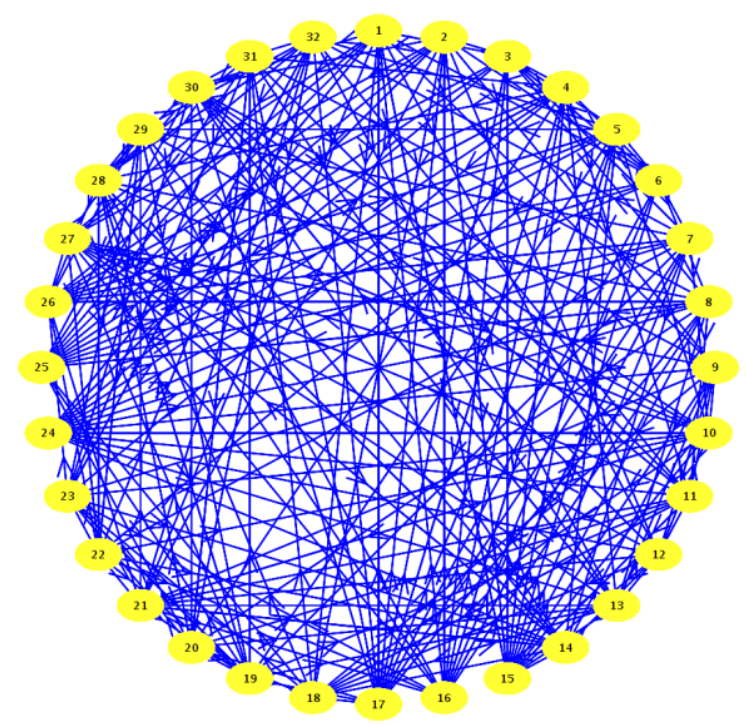

Figure 2 The zero divisor graph of the finite ring $R_{2}$

\subsection{CONCLUSION}

In this study, the zero divisors are determined for two finite rings, which are the ring of $2 \times 2$ matrices over integers modulo two and three, $R_{1}=M_{2}\left(\mathbb{Z}_{2}\right)$ and $R_{2}=M_{2}\left(\mathbb{Z}_{3}\right)$. Then, probability that two elements of a ring have product zero, $P(R)$ is determined for both rings. Finally, the zero divisor graph of the rings are constructed. The results are summarized in the following Table 1.

Table 1 The summary of this study

\begin{tabular}{|c|c|c|c|c|}
\hline Ring & $\begin{array}{c}\text { The } \\
\text { number } \\
\text { of zero } \\
\text { divisors } \\
\text { of } R, \\
|Z(R)|\end{array}$ & $\begin{array}{c}\text { The } \\
\text { number of } \\
\text { annihilators } \\
\text { of } R, \\
|A n n(R)|\end{array}$ & $\begin{array}{c}\text { The } \\
\text { probability } \\
\text { that two } \\
\text { elements } \\
\text { of } R \text { has } \\
\text { product } \\
\text { zero, } P(R)\end{array}$ & $\begin{array}{c}\text { The zero } \\
\text { divisor } \\
\text { graph, } \\
\Gamma(R)\end{array}$ \\
\hline$R_{1}$ & 9 & 58 & $\frac{29}{128}$ & $\begin{array}{c}\text { Nine } \\
\text { vertices } \\
\text { and } 24 \\
\text { arcs }\end{array}$ \\
\hline$R_{2}$ & 32 & 417 & $\frac{139}{2187}$ & $\begin{array}{c}32 \\
\text { vertices } \\
\text { and } 248 \\
\text { arcs }\end{array}$ \\
\hline
\end{tabular}

\section{Acknowledgement}

The authors would like to acknowledge Universiti Teknologi Malaysia (UTM) for the financial support of this research through UTM Fundamental Research Grant, Vote number 20H70. The first author would also like to express her gratitude to UTM and the Ministry of Higher Education, Malaysia for the financial funding through UTM Zamalah Scholarship.

\section{References}

[1] Hebisch, U. and Weinert, H. J. 1998. Semirings: Algebraic Theory and Applications in Computer Science. World Scientific Publishing: Singapore.

[2] Hurley, B. and Hurley, T. 2011. Group Ring Cryptography. International Journal of Pure and Applied Mathematics. 69(1): 67-86.

[3] Garces, Y., Torres, E., Pereira, O. and Rodriguez, R. 2014. Application of the Ring Theory in the Segmentation of Digital Images. Arxiv, arxiv.org/pdf/1402.4069.pdf

[4] Fraleigh, J. B. and Katz, V. 2003. A First Course in Abstract Algebra. $7^{\text {th }}$ Edition. Addison-Wesley. 
[5] Matsumura, H. 1989. Commutative Ring Theory. University Press: Cambridge.

[6] Gustafson, W. H. 1973. What is the Probability that Two Group Elements Commute. The American Mathematical Monthly. 80(9): 1031-1034.

[7] Dutta, J., Basnet, D. K. and Nath, R. K. 2017. On Commuting Probability of Finite Rings. Indagationes Mathematicae. 28: 372-382.

[8] Riaz, F. and Ali, K. M. 2011. Applications of Graph Theory in Computer Science. 2011 Third International Conference on Computational Intelligence, Communication Systems and Networks. 142-145.

[9] Essam, J. W. 1971. Graph Theory and Statistical Physics. Discrete Mathematics. 1 (1): 83-112.

[10] Balaban, A. T. 1985. Applications of Graph Theory in Chemistry. Journal of Chemical Information and Modeling. 25(3): 334-343.

[11] Sarmin, N. H., Mohd Noor, A. H. and Omer, S. M. S. 2017. On Graphs Associated to Conjugacy Classes of Some Three-Generator Groups. Jurnal Teknologi. 79(1): 55-61.

[12] Andeson, D. F., Axtell, M. C. and Stickles, J. A. 2010. Zerodivisor Graphs in Commutative Rings. Commutative Algebra. 23-45.

[13] Rowen, L. H. 1988. Ring Theory. Vol. 1. Academic Press Inc: Boston.

[14] Sherman, G. 1975. What is the Probability an Automorphism Fixes a Group Element. The American Mathematical Monthly. 82(3): 261-264.
[15] Erfanian, A., Rezaei, R. and Lescot, P. 2007. On the Relative Commutativity Degree of a Subgroup of a Finite Group. Communications in Algebra. 35: 4183-4197.

[16] Zamri, S. N. A., Sarmin, N. H., Khasraw, S. M. S., El-sanfaz, M. A. and Rahmat, H. 2017. On the Commutativity Degree of Metacyclic Groups of 5-Power Order Using Conjugation Action. Malaysian Journal of Fundamental and Applied Sciences. 13(4): 784-787.

[17] MacHale, D. 1976. Commutativity in Finite Rings. The American Mathematical Monthly. 83(1): 30-32.

[18] Buckley, S. M., Machale, D. and Aine, N. S. 2014. Finite Rings with Many Commuting Pairs of Elements. Preprint.

[19] Khasraw, S. M. S. 2020. What is the Probability that Two Elements of a Finite Ring have Product Zero? Malaysian Journal of Fundamental and Applied Sciences. 16(4): 497499.

[20] Bondy, J. and Murty, U. 1976. Graph Theory with Applications. Elsevier Science Publishing Co., Inc: New York.

[21] Rosen, K. H. 2004. Handbook of Graph Theory. CRC Press: United States of America.

[22] Anderson, DF. and Livingston, P. S. 1999. The Zero-Divisor Graph of a Commutative Ring. Journal of Algebra. 217: 434-447.

[23] Redmond, S. P. 2002. The Zero-Divisor Graph of a NonCommutative Ring. International Journal of Commutative Rings. 1 (4): 203-211. 